\title{
Van Gölü’nde Sedimantasyon Hızının Fizyografik Değişimi, Doğu Anadolu/Türkiye
}

\author{
Ayşegül Feray MEYDAN*, Sefer ÖRÇEN \\ Van Yüzüncü Yıl Üniversitesi, Jeoloji Mühendisliği Bölümü, Van \\ (ORCID: 0000-0002-3842-1711) (ORCID: 0000-0002-6099-7725)
}

\begin{abstract}
$\ddot{O} \mathbf{z}$
Gölsel çökel istifler geçmişte olmuş iklimsel, tektonik, volkanik, su seviyesi değişimleri ve sedimantasyon hızı gibi değişikliklerin kayıtlarının tutulduğu önemli arşivlerdir. Van Gölü dip çökelleri karasal olarak uzun bir geçmişi simgelemesi nedeni ile bu tip çalışmalar için karakteristik bir örneği temsil etmektedir. Gölsel çökel istifler farklı disiplinlerde çalışılırken kronolojik olarak yaşlandırılması gerekmektedir. Bu açıdan farklı birçok yaşlandırma metodu mevcuttur. Bu çalışma kapsamında, Van Gölü'nün farklı fizyografik bölgelerinden alınan altı adet kısa karot üzerinde dengeüstü ${ }^{210} \mathrm{~Pb}$ aktiviteleri hesaplanmış ve CRS modeline göre ortalama sedimantasyon hızı belirlenmiştir. ${ }^{137} \mathrm{Cs}$ aktivitesi bu çalışma kapsamında kronostratigrafik referans $(1963,1986)$ olarak kabul edilmiş ve hesaplanan sedimantasyon oranları ile uyumlu bulunmuştur. Hesaplanan sedimantasyon hızları 0.5 $\mathrm{mm} / \mathrm{y} ı 1$ ile $1.3 \mathrm{~mm} / \mathrm{y} ı$ arasında değişmektedir. Sedimantasyon hızlarındaki farklılığın sadece su derinliği ve drenaj havzası kontrollü olmadığı bununla birlikte göl tabanındaki morfolojik unsurların kontrolü altında olduğu ortaya konmuştur.
\end{abstract}

Anahtar kelimeler: Van Gölü, ${ }^{210} \mathrm{~Pb}-{ }^{137} \mathrm{Cs}$, sedimantasyon oran1, morfoloji

\section{Physiographic Variations of Sedimentation Rate in Lake Van, Eastern Anatolia/Turkey}

\begin{abstract}
Lacustrine sedimentary sequences are important archives that keep records of past climatic, tectonic, volcanic, lake level and sedimentation rate changes. Lake Van sediments represent a characteristic example of this type research because it represents a long terrestrial history. The lacustrine sediments should be dated chronologically while working in different disciplines. There are many different dating methods. In this study, on the six cores taken from the different physiographic regions of Lake Van, unsupported ${ }^{210} \mathrm{~Pb}$ activities were calculated and the average sedimentation rate was determined according to the CRS model. ${ }^{137} \mathrm{Cs}$ activity was accepted as chronostratigraphic marker $(1963,1986)$ and it was found that the dates are compatible with the calculated sedimentation rates. The calculated sedimentation rates are between $0.5 \mathrm{~mm} /$ year and $1.3 \mathrm{~mm} / \mathrm{year}$. The differences in sedimentation rates were not only controlled by water depth and drainage basin, but also by the morphological elements at the lake basin.
\end{abstract}

Keywords: Lake Van, ${ }^{210} \mathrm{~Pb}-{ }^{137} \mathrm{Cs}$, sedimentation rate, morphology

\section{Giriş}

Göl sedimanları geçmiş ortam koşullarının saklandığı arşivleri kesintisiz olarak barındırmaktadırlar. Bu nedenle son yıllarda göllerde yapılan paleolimnolojik çalışmalar, başta geçmiş iklim değişikliklerinin açıklığa kavuşturulması gibi birçok bilimsel araştırmanın odağı olmaktadır. Paleolimnolojik araştırmalarda, sedimanların depolanma hızının belirlenmesi çok önemli bir parametredir. Sedimantasyon hızı geleneksel yöntemlerin yanında hidrografik haritalar, fiziksel ölçümler ve

*Sorumlu yazar: feraygokdere@yyu.edu.tr

Geliş Tarihi: 28.03.2019, Kabul Tarihi: 01.07.2019 
izotopların kullanıldığı yeni yöntemlerle ölçülebilmektedir. Sedimanların güncel sedimantasyon hızının $(<150$ yıl $)$ belirlenmesinde en yaygın kullanılan metot ${ }^{210} \mathrm{~Pb}$ yöntemidir. ${ }^{210} \mathrm{~Pb}$, yeryüzünde düzenli dağ 11 lı gösteren ${ }^{238} \mathrm{U}$ serisinin bir üyesidir ve yarılanma ömrü 22.3 yıldır. Bu tarihlendirme yöntemi, ${ }^{222} \mathrm{Rn}$ gazının topraktan atmosfere salınması temeline dayanmaktadır. Kısa ömürlü ${ }^{222} \mathrm{Rn}$ (3.82 gün) ${ }^{210} \mathrm{~Pb}$ 'ye bozunur ve ${ }^{210} \mathrm{~Pb}$ haftalar içerisinde katı bir serpinti olarak dünya yüzeyine veya su rezervuarına geri döner. ${ }^{210} \mathrm{~Pb}$ aktivitesi, ${ }^{226} \mathrm{Ra}$ 'nın doğal bozunmasıyla oluşan dengedeki ${ }^{210} \mathrm{~Pb}$ ve atmosferik serpinti ile oluşan dengeüstü ${ }^{210} \mathrm{~Pb}$ olmak üzere iki bileşenlidir. Sedimantasyon hızı hesaplanırken dengeüstü ${ }^{210} \mathrm{~Pb}$ profilinden faydalanılmaktadır. Bir sediman tabakası yeni çökelen malzemenin altına gömüldüğünden, dengeüstü aktivitesi doğal bozunma yasasında olduğu gibi azalır [1]. Kilit nokta, sedimanın yaşını iyi bir doğrulukla belirlemeye izin veren başlangıç aktivitesinin tahminidir. Bu sorunu çözmek için birçok model kullanılmaktadır. Yaygın olarak kullanılan ve CRS (Constant Rate of Supply) olarak adlandırılan model, değişen sediman birikim hızına karşılık sedimana aktarılan ${ }^{210} \mathrm{~Pb}$ akısının sabit olduğunu varsaymaktadır [2]. Taşkın olayları veya arazi kullanımındaki değişim nedeni ile yukarıda sözü edilen modellerde kullanılan ${ }^{210} \mathrm{~Pb}$ akısının konsantrasyonunda hatalar olabilir. $\mathrm{Bu}$ nedenle ${ }^{210} \mathrm{~Pb}$ modeli, ${ }^{137} \mathrm{Cs}$ yapay radyonüklid serpintisinin bağımsız olarak ölçümü ile doğrulanabilir [1]. ${ }^{137} \mathrm{Cs}$ radyonüklid serpintisi ilk olarak 1950 'li y1lların başında ilk nükleer silah denemeleri ile ortaya çıkmıştır. 1965 yılında nükleer silah denemeleri ve 1986 yılında meydana gelen Çernobil kazasında atmosferde en yüksek değerlere ulaşmıştır [1].

Van Gölü özellikle son yıllarda başta ICDP-PaleoVan projesi olmak üzere birçok paleolimnolojik araştırmaya ev sahipliği yapmıştır. 2004, 2012 ve 2014 yıllarında yapılan sismik araştırmalar neticesinde göl tabanı morfolojisi ve gölün batimetrisi ortaya konulmuştur [3-5]. Bu çalışmanın amacı sismik araştırmalarla varlığı belirlenmiş olan gölün farklı fizyografik bölgelerinden alınan kısa karotların güncel sedimantasyon oranlarının belirlenmesi ve bu oranların birbirleri ve taban morfolojisi ile olan ilişkisini ortaya koymaktır. Bu amaçla karotların ${ }^{210} \mathrm{~Pb}$ aktivite profillerine $\mathrm{CRS}$ modeli uygulanarak sedimantasyon oranları hesaplanmış ve bu oranların doğruluğu ${ }^{137} \mathrm{Cs}$ aktivitesinden elde edilen kronostratigrafik referans tarihleri ile kıyaslanmıştır. Elde edilen sedimantasyon oranları arasındaki ilişki, morfolojik unsurlar ile açıklanmıştır.

\section{Materyal ve Metot}

\section{1. Çalışma Alanı ve Sediman Karotlar}

Doğu Anadolu'nun doğusunda deniz seviyesinden 1648 metre yükseklikte yer alan Van Gölü, alansal açıdan dünyanın en büyük sodalı gölü $\left(3570 \mathrm{~km}^{2}\right)$ ve hacimsel açıdan $\left(607 \mathrm{~km}^{3}\right)$ dördüncü en büyük kapalı havza gölüdür (Şekil 1). Maksimum derinliği 460 metre olan gölün suları $9.7 \mathrm{pH}$ ve $21 \mathrm{~g} / \mathrm{kg}$ tuzluluğa sahiptir [6, 7]. Van Gölü'nün drenaj havzası içerisinde güneyde Bitlis-Pötürge masifine ait metamorfik kayaçlar, doğusunda ise Tersiyer ve Kuvaterner yaşlı konglomeralar, karbonatlar ve kumtaşları yüzlek vermektedir. Kuzey ve batısı ise volkanik kayaçlar ile örtülüdür [8,9]. Göl havzası tektonizma açısından oldukça aktif bir bölgede şekillenmiştir [10,11]. Gölün kuzeyinde Süphan Volkanı $(4058 \mathrm{~m})$ ve batısında Nemrut Volkanı $(2948 \mathrm{~m})$ yer almaktadır. Bu volkanlardan türeyen yaklaşık 500 tefra seviyesi göl tabanında volkanik olmayan sedimanlar içerisinde katmanlamıştır $[12,13]$. Bununla birlikte Van Gölü'nün evrimini ve bölgedeki iklim değişikliklerini araştıran ICDP-PaleoVan çalışmalarının sonuçlarına göre; göl havzası 600 bin yıl önce Nemrut Volkanının Muş Havzası'nın önünü kapatmasıyla oluşmaya başladığı bildirilmiştir [4, 14]. 


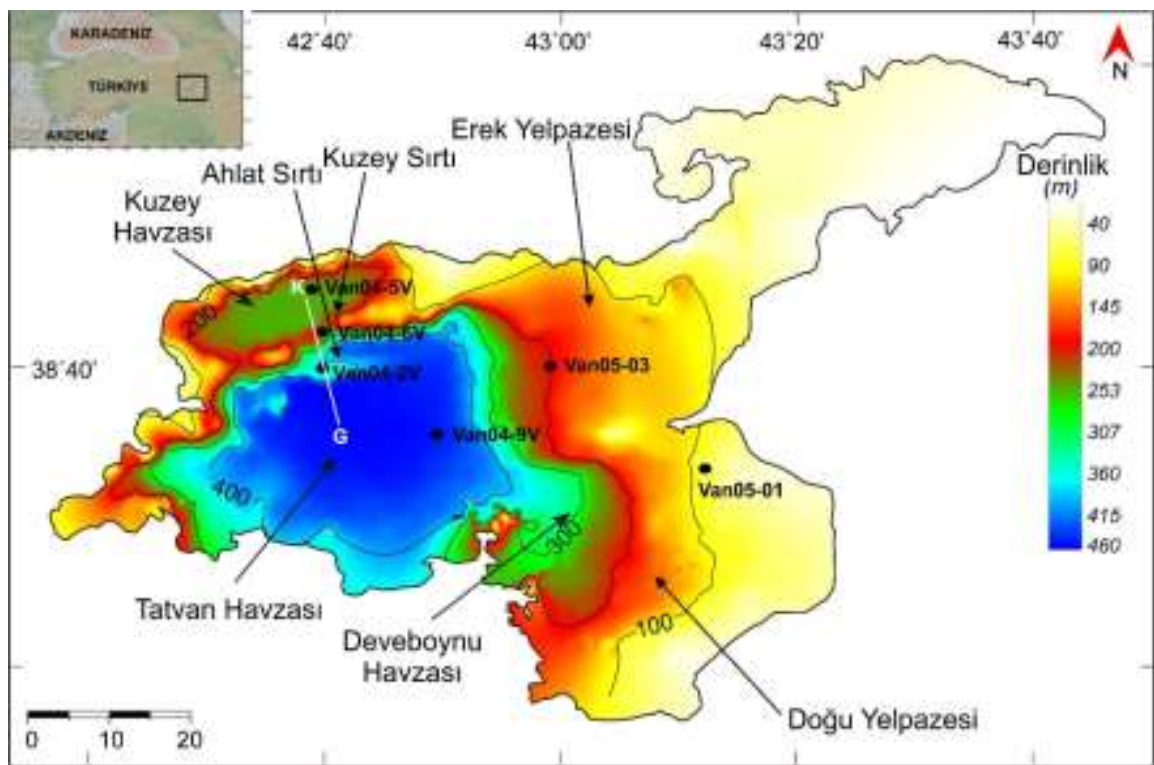

Şekil 1. Çalışma alanı, karotların ve şekil 2'deki G-K profil hattı lokasyonunu gösteren batimetrik harita ([4]'den değiştirilerek alınmıştır)

Yapılan sismik araştırmalar sonucunda elde edilen verilere göre, Van Gölü’nün taban morfolojisi şelf, yamaç ve derin göl havzası olmak üzere üçe ayrılmıştır [3, 15]. Gölün şelf olarak tanımlanan kısımlarında su derinliği 150 metreden daha azdır ve şelflerin genişliği gölün kuzey, güney ve batı kesimlerinde $10 \mathrm{~km}$ 'den daha az fakat doğu kesimlerinde $20 \mathrm{~km}$ 'ye ulaşmaktadır [4]. Ayrıca doğu şelfinde göl suyunun daha düşük evrelerinde oluştuğu düşünülen erozyonel kökenli sualtı kanalları tanımlanmıştır [5]. Gölsel yamacın eğimi doğu şelfinde $1-2^{0}$ iken kuzey ve güneyde bu eğim $10^{\circ}$ ye kadar çıkmaktadır. Gölün en derin noktasını içine alan Tatvan Havzası 400 metre batimetrik kontörü ile belirlenmiştir, nisbeten daha düz bir morfoloji göstermektedir ve küçük olan Ahlat alt havzasından Ahlat sırtı ile ayrılmaktadır [4]. Tatvan Havzası, küçük olan Ahlat alt havzasından Ahlat sırtı ile ayrılmaktadır (Şekil 2). Yaklaşık $90 \mathrm{~km}^{2}$ alana ve 240 metre su derinliğine sahip Kuzey Havzası, Tatvan Havzası'ndan $30 \mathrm{~km}$ uzunluğunda ve $5 \mathrm{~km}$ genişliğinde Kuzey Sırtı ile ayrılmaktadır. Deveboynu olarak tanımlanan alt havzanın uzunluğu D-B doğrultusunda $1.5 \mathrm{~km}$ ve K-G doğrultusunda $6 \mathrm{~km}$ ve su derinliği 300 m'dir [5].

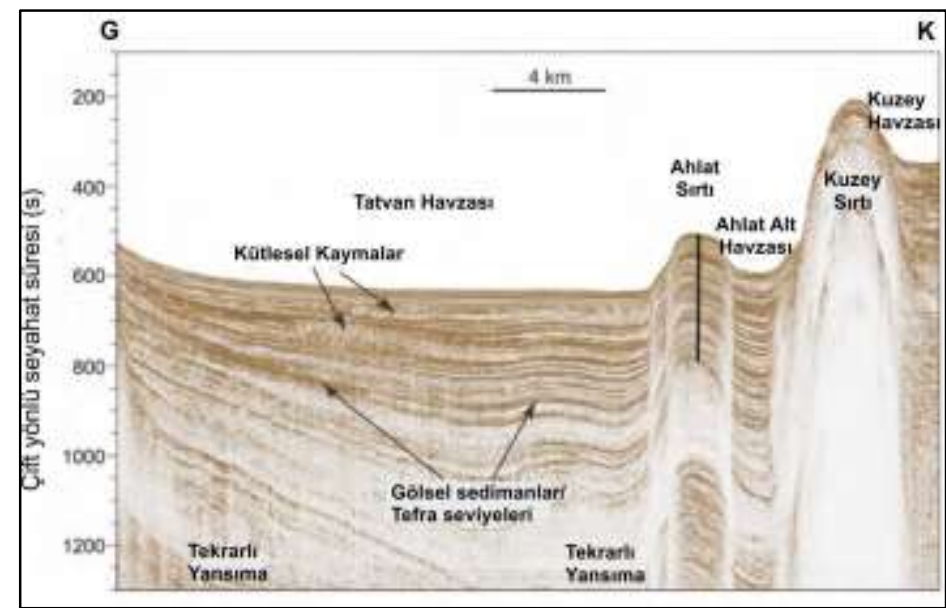

Şekil 2. Tatvan Havzası, Ahlat Sırtı, Ahlat Havza alt havzası ve Kuzey Havzasından geçen G-K yönlü sismik profil ([16]'dan değiştirilerek alınmıştır)

$\mathrm{Bu}$ çalışma kapsamında karotlar gölün farklı fizyografik bölümlerinden (Tablo 1), UWITEC marka gravite karotiyer ile serbest düşme yöntemi ile alınmıştır. Karotiyerin ucuna dış çapı $65 \mathrm{~mm}$ olan şeffaf tüpler kullanılmıştır. Çakma yönteminin aksine bu yöntem ile karot alımı esnasında sedimanlarda 
meydana gelebilecek deformasyonun önüne geçilebilmektedir. Alınan sediman karotlara ait konumlar (Şekil 1) ve bu karotlara ait detaylı bilgiler verilmiştir (Tablo 1).

Tablo 1. Kisa karotların özellikleri

\begin{tabular}{cccc}
\hline Karot No & Koordinat (N/E) & Havza & Karot Su Derinliği (m) \\
\hline Van04-2V & $38^{\circ} 39.939^{\prime} / 42^{\circ} 40.214^{\prime}$ & Ahlat Sirtı & 375 \\
Van04-5V & $38^{\circ} 44.929^{\prime} / 42^{\circ} 39.429^{\prime}$ & Kuzey Havzası & 247 \\
Van04-6V & $38^{\circ} 43.017^{\prime} / 42^{\circ} 39.879^{\prime}$ & Kuzey Sirtı & 145 \\
Van04-9V & $38^{\circ} 35.813^{\prime} / 42^{\circ} 49.665^{\prime}$ & Tatvan Havzasi & 420 \\
Van05-01 & $38^{\circ} 33.437^{\prime} / 43^{\circ} 10.038^{\prime}$ & Doğ Şelfi & 50 \\
Van05-03 & $38^{\circ} 40.144^{\prime} / 42^{\circ} 54.471^{\prime}$ & Erek Yelpazesi & 216 \\
\hline
\end{tabular}

\subsection{Analitik Metotlar}

Alınan sediman karotlar iki kısıma ayrılmış ve ilk $10 \mathrm{~cm}$ lik kısmı her yarım cm'de bir örneklenmiştir. Diğer kısım sonraki çalışmalar için soğutucu odada $+4^{0} \mathrm{C}$ 'de saklanmıştır. Örneklemesi yapılan sedimanların yaş ağırlıkları hesaplanmıştır. Örnekler donduruduktan sonra liyofilizatör cihazı ile içeriğindeki su uzaklaştırılmış ve kuruması sağlanmıştır. Kurutulmuş örnekler pudra haline getirilmiş ve ardından Canberra marka çok kanallı analizörüne bağlı HPGe kuyu tipi dedektörü (High Purity Ge well dedector) ile gama sayımı yapılmıştır. ${ }^{210} \mathrm{~Pb}$ için veriler $46.5 \mathrm{keV}$ 'deki gama sprektrometresi ile tespit edilirken, ${ }^{137} \mathrm{Cs}$ için veriler $662 \mathrm{keV}$ gama enerjisi kullanılarak elde edilmiştir. Analizler Zürih/İsviçre'de bulunan Eawag Enstitüsü, Yüzey Suları Araştırmaları ve Yönetimi Bölümü (EAWAG/ Department Surface Waters Research and Management) Laboratuvarı'nda gerçekleştirilmiştir.

$\mathrm{Bu}$ çalışma kapsamında sedimantasyon oranı hesaplanırken CRS modeli kullanılmıştır. CRS modeli, atmosferden deniz suyuna sabit bir ${ }^{210} \mathrm{~Pb}$ akısı olduğunu varsaymaktadır. $\mathrm{Bu}$ durumda sedimantaston hızında oluşabilecek herhangi bir değişkenlikten bağımsız olarak, sedimanların ${ }^{210} \mathrm{~Pb}$ akısı sabittir [17]. Bu modelin geçerli olduğu durumlarda; sedimanın " $t$ " yaşına bağlı olarak dengeüstü ${ }^{210} \mathrm{~Pb}(\mathrm{~A})$ konsantrasyonundaki değişim aşağıdaki bağlantıda verilir [2].

$$
A=A(0) e^{-\lambda t}
$$

$\mathrm{A}(0)$ sediman kolonundaki toplam dengeüstü ${ }^{210} \mathrm{~Pb}$ aktivitesidir ve $\lambda,{ }^{210} \mathrm{~Pb}$ 'nin radyoaktif bozunma sabitidir $(\lambda=-0,0311)$. A ve $\mathrm{A}(0),{ }^{210} \mathrm{~Pb}$ profilinin sayısal integrali kullanılarak direk hesaplanabilmektedir. $\mathrm{x}$ derinliğinin yaşı $t$ olmak üzere;

$$
t=\frac{1}{\lambda} \ln \frac{A(0)}{A}
$$

formülü ile ve sedimantasyon oranı CRS modeline göre aşağıdaki formül ile hesaplanmıştır [2].

$$
r=\frac{\lambda A}{C}
$$

Yarılanma ömrü 30.1 y1la denk gelen ${ }^{137} \mathrm{Cs}$, Cs izotopunun radyoaktif izotopudur ve atmosferdeki ${ }^{137} \mathrm{Cs}$ radyonüklidi yağışlarla yeryüzüne inmekte ve kil tanelerinin yapısına hızlıca hapsolmaktadır. Daha sonra bu taneler erozyonla birlikte göllerin tabanında depolanır. Bu çalışmada kronostratigrafik referans tarihi olarak ${ }^{137} \mathrm{Cs}$ radyonüklidi kullanılmıştır. Çünkü atmosferde 50 'li yıllardan önce sıfır olan ${ }^{137} \mathrm{Cs}$ serpintisi, nükleer denemelerle atmosfere salınım yapmaya başlamıştır. 1963 nükleer testler nedeni ile atmosferde ilk yüksek değeri verirken, ikinci yüksek piki 1986 Çernobil Nükleer kazası ile vermiştir. Bu nedenle ${ }^{137} \mathrm{Cs}$ profillerine bakıldığı zaman 1963 ve 1986 yılları kolaylıkla ayırt edilebilmektedir. 


\section{Bulgular ve Tartışma}

Çalışma kapsamında alınan tüm karotlar için ayrı ayrı dengeüstü ${ }^{210} \mathrm{~Pb}$ ve ${ }^{137} \mathrm{Cs}$ aktivitelerinin derinliğe göre değişimi hesaplanmış ve grafiklerde verilmiştir (Şekil 3). Genel radyoaktif bozunma yasalarına göre sedimanın üst yüzeyinden daha alt katmanlara doğru dengeüstü ${ }^{210} \mathrm{~Pb}$ konsantrasyonunun azalmas1 gerekmektedir. Tüm karotlarda dengeüstü ${ }^{210} \mathrm{~Pb}$ aktivitesinin derinliğe bağlı üssel olarak azalma gösterdiği gözlenmiştir $\left(\mathrm{R}^{2}>0.46\right)$ ve bu durum genel radyoaktif bozunma yasaları ile uyumludur.

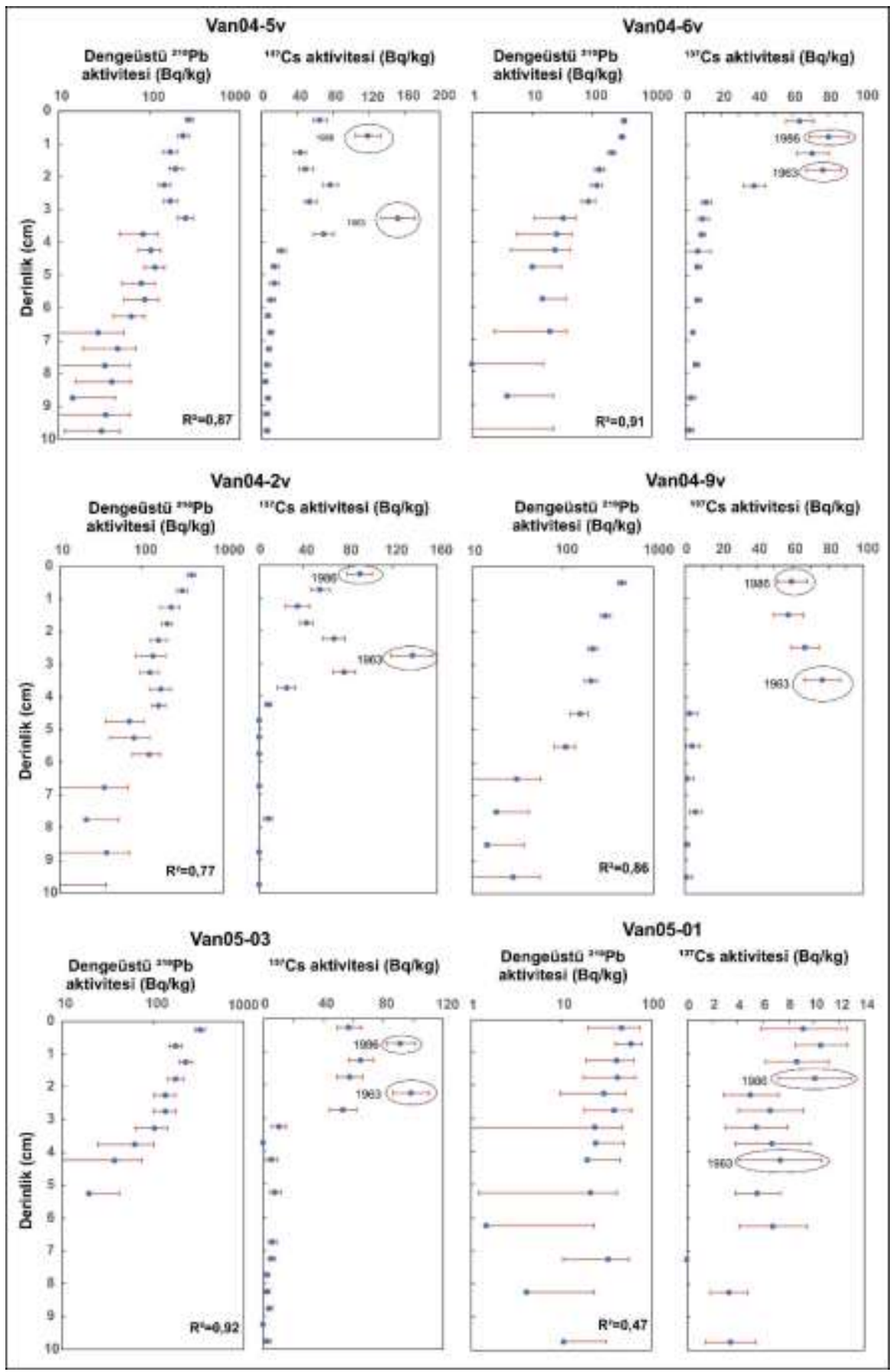

Şekil 3. Karotlardan elde edilen dengeüstü ${ }^{210} \mathrm{~Pb},{ }^{137} \mathrm{Cs}$ aktiviteleri

Buna göre gölün farklı fizyografik bölgelerinden alınan karotlardan elde edilen toplam dengeüstü ${ }^{210} \mathrm{~Pb}$ aktivitesi, ${ }^{137} \mathrm{Cs}$ aktivitesi ve CRS modeline göre hesaplanan ortalama güncel sedimentasyon oranları aşağıda verilmiştir (Tablo 2). Bu oranlara göre, Van Gölü’nün farklı fizyografik 
bölümlerinden elde edilen sedimantasyon oranlarının birbirinden farklı olduğu bulunmuştur. ${ }^{137} \mathrm{Cs}$ yapay bir radyonüklidtir ve önceden sözü edildiği gibi atmosferde nükleer silah denemelerinin 50'li yıllarda başlaması ile gözlenmeye başlamış ve 1963 yılında ilk yüksek değeri vermiştir. Daha sonra 1986 yılı Çernobil Kazası ile ikinci yüksek piki vermiştir. Kronostratigrafik referans (1963 ve 1986) olarak kullanılan ${ }^{137} \mathrm{Cs}$ aktivitesinde gözlenen pik noktaları, dengeüstü ${ }^{210} \mathrm{~Pb}$ profillerinden yola çıkılarak ve CRS modeli ile elde edilen sedimantasyon oranlarının doğruluğunu desteklemektedir. Karot profillerindende dikkati çekeceği üzere daha derinlerde ${ }^{137} \mathrm{Cs}$ aktivitesi sıfırdır.

Tablo 2. Toplam dengeüstü ${ }^{210} \mathrm{~Pb},{ }^{137} \mathrm{Cs}$ aktivitesi ve sedimantasyon oranları

\begin{tabular}{ccccc}
\hline Karot No & Havza & $\begin{array}{c}\text { Dengeüstü toplam } \\
\text { 210 Pb aktivitesi } \\
(\mathrm{Bq} / \mathrm{kg})\end{array}$ & $\begin{array}{c}\text { Toplam }{ }^{137} \mathrm{Cs} \\
\text { aktivitesi }(\mathrm{Bq} / \mathrm{kg})\end{array}$ & $\begin{array}{c}\text { Sedimantasyon } \\
\text { Oran1 } \\
(\mathrm{mm} / \mathrm{yl})\end{array}$ \\
\hline Van04-2V & Ahlat Sırtı & $2330 \pm 653$ & $546 \pm 92$ & 0.7 \\
Van04-5V & Kuzey Havzası & $2212 \pm 596$ & $752 \pm 126$ & 1.1 \\
Van04-6V & Kuzey Sirt1 & $1356 \pm 352$ & $400 \pm 70$ & 0.5 \\
Van04-9V & Tatvan Havzas1 & $1532 \pm 325$ & $278 \pm 54$ & 0.6 \\
Van05-01 & Doğu Şelfi & $395 \pm 313$ & $89 \pm 32$ & 1.3 \\
Van05-03 & Erek Yelpazesi & $1417 \pm 355$ & $470 \pm 82$ & 0.6 \\
\hline
\end{tabular}

Su derinliklerine göre elde edilen sedimantasyon oranları aşağıdaki grafikte karşılaştırılmalı olarak verilmiştir (Şekil 4). Üzerinde çalışılan karotlardan hesaplanan en hızlı sedimantasyon oranı 1.3 $\mathrm{mm} / \mathrm{y}$ 1l ile doğu şelfinden alınan Van05-01 karotundan elde edilmiştir. Bu noktadaki sedimantasyon oranının göreceli olarak hızlı olmasını akarsu kontrolünün bu bölgede yoğun olması ve akarsuların bol miktarda malzemeyi bu noktada biriktirmesine bağlamak mümkündür. Aynı zamanda bu noktanın kıyıya yakın olması ve bu bölgede insan etkisinin (tarım faaliyetleri, yapılaşma vs) son yıllarda gözle görülür biçimde artmış olması sedimantasyon hızını artıran diğer nedenler arasında sayılabilir.

Erek yelpazesinden alınan karotun (Van05-03) sedimantasyon hızı oldukça düşüktür $(0.6$ $\mathrm{mm} / \mathrm{y} 1$ l). Bu durumu karot alınan noktanın akarsu kontrolünden uzak olmasına bağlamak mümkündür. Bununla birlikte bu nokta fizyografik olarak gölsel yamaç olarak tanımlanan bölgede yer almaktadır [5]. Buradan yola çıkarak bu noktadaki eğim düşünülecek olursa, malzemenin burada çökelmeyeceği ve yamaç aşağı hareket ederek uygun koşullar altında çökeleceği sonucuna ulaşılabilir.

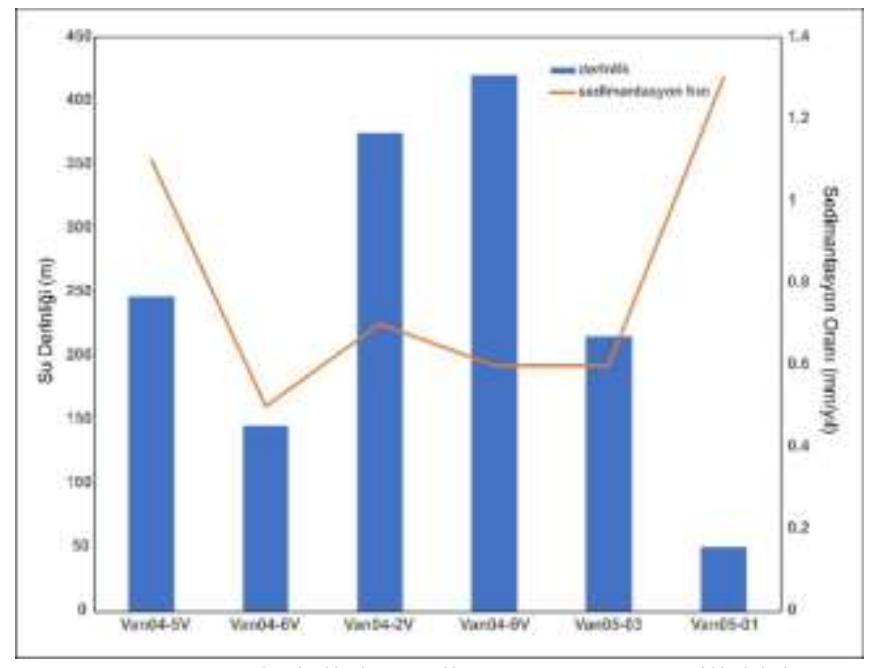

Şekil 4. Su derinliği - sedimantasyon oranı ilişkisi

Kuzeyden güneye doğru (Van 04-5V, Van04-6V, Van04-2V, Van04-9V; Şekil 2) elde edilen sedimantasyon oranları $1.1 \mathrm{~mm} / \mathrm{y} 1 \mathrm{l}$ ile $0.5 \mathrm{~mm} / \mathrm{y} 1 \mathrm{l}$ arasında değişmektedir. Bu aralıkta önceden yapılan çalışmaların sonucuna göre drenaj havzasının kontrolü ve su derinliği düşünüldüğünde sedimantasyon oranının azalması beklenmektedir $[4,5]$. Ancak elde edilen sedimantasyon oranları sirasıly, $1.1 \mathrm{~mm} / \mathrm{y} 1 \mathrm{l}$ (Kuzey Havzası), $0.5 \mathrm{~mm} / \mathrm{y} 1$ (Kuzey Sırtı), $0.7 \mathrm{~mm} / \mathrm{y} 1 \mathrm{l}$ (Ahlat Sirtı) ve $0.6 \mathrm{~mm} / \mathrm{y} 1$ (Tatvan Havzası) şeklindedir. Bu hat üzerinde su derinliği ve sedimantasyon hızı arasında anlamlı bir ilişki bulunmamıştır $(r=-0,019)$. Kuzey Havzası'ndan elde edilen karotun sedimantasyon oranı kıyıya yakın olması nedeni 
ile bol miktarda malzemenin erozyon ile taşınmasından dolayı yüksektir $(1.1 \mathrm{~mm} / \mathrm{y} ı 1)$. Bunu takiben Kuzey Sırtı'ndan elde edilen sedimantasyon oranı $0.5 \mathrm{~mm} / \mathrm{y} 1 \mathrm{l}$ dır. Su derinliğinin göreceli olarak az olmasına rağmen sedimantasyon oranı düşmüştür. Bu durumu Kuzey Sırtı'nın morfolojisine bağlamak mümkündür. Kuzey Sırtı morfolojik olarak Kuzey Havzası'ndan taşınarak gelen malzemenin büyük bir kısmının önünü kapatarak güneye doğru taşınmasını engellemektedir ve güneydeki havzalarda sedimantasyon oranını düşürmektedir şeklindeki kanı doğruluk kazanmaktadır. Ahlat sırtında sedimantasyon oranı tekrar artmaktadır ve $0.7 \mathrm{~mm} / \mathrm{y} 1 \mathrm{l}$ olarak elde edilmiştir. Van Gölü'nde gerçekleştirilen önceki çalışmalara göre son 600 bin yıllık süreçte ${ }^{14} \mathrm{C}$ ve Ar-Ar metoduyla yaşlandırması yapılan karotlardan elde edilen verilere göre Kuzey Havzası'ndaki sedimantasyon oranının Ahlat Sırtına oranla 3.5 kat daha hızlı olduğu söylenmiştir [4, 18]. Bu çalışmalara göre; Kuzey Havzası'nda sedimantasyon hızının fazla olması farklı nedenlere bağlanmıştır. Bunlardan biri, bu havzanın Nemrut Volkanı'na yakınlığı ve bu nedenlede volkanoklastiklerin taşınarak burada çökelmesi ve sedimantasyon oranını yükseltmesidir. Bir diğeri ise Kuzey Sırtı'nın Ahlat Sırtı ve Tatvan Havzası'na volkanoklastiklerin taşınmasına engel olan bir bariyer görevinin görmüş olabileceği ve Ahlat Sırtı ile Tatvan Havzasında sedimantasyon oranının bu nedenle nisbeten daha düşük olduğu düşünülmektedir [5]. Bizim çalışmamıza göre son 150 yıllık süreçte bu oran 1.5 kata düşmektedir. Bu azalmanın nedenini volkanik aktivitenin günümüzde gözlenmemesi ve yağış miktarının düşmesine bağlamak mümkündür.

Tatvan Havzasında elde edilen sedimantasyon oranı $0.6 \mathrm{~mm} / \mathrm{y} ı 1$ 'dır. Önceki çalışmalardan elde edilen ve varv sayımı ile yaşlandırması yapılan karotların sedimantasyon oranı Tatvan Havzası için 0.5 mm/yıl'dır [19, 20]. Sedimantasyon oranlarının önceki çalışmalar ve bu çalışmadaki farklı çıkmasının nedenini yaşlandırma yönteminin ve karot alınan noktanın farklı olmasına bağlamak mümkündür.

\section{Sonuç ve Öneriler}

Van Gölü'nün farklı fizyografik bölgelerinden elde edilen karotların sedimantasyon oranlar ${ }^{210} \mathrm{~Pb}-{ }^{137} \mathrm{Cs}$ radyonüklid kronolojisine göre CRS modeli kullanılarak belirlenmiştir. Elde edilen sonuçlara göre akarsu kontrolü ve insan etkisinin (yapılaşma, tarım faaliyetleri vs) yoğun olduğu kıyıya yakın bölgeden elde edilen sedimantasyon oranının derin havzalara göre daha hızlı olduğu ortaya konulmuştur. Bununla birlikte bugüne değin farklı göllerde yapılan benzer çalışmalarda sedimantasyon oranını kontrol eden faktörlerin özellikle su derinliği ve/veya drenaj havzası ve insan etkisinin kontrolü altında olduğu vurgulanmıştır. Fakat bu çalışma kapsamında yapılan çalışmaların sonuçlarına göre sedimantasyon oranını kontrol eden bir başka faktörün göl tabanında yer alan morfolojik yapılar olduğu ve bu yapıların sedimantasyon oranını değiştirebileceği ortaya koymuştur. Bu nedenle Van Gölü ve diğer tüm göllerde yapılacak paleolimnolojik çalışmalarda tek bir karot üzerinden tüm göl tabanındaki sedimalara yaş vermek doğru bir yaklaşım değildir. Bunun için öncelikle göl tabanı morfolojisinin iyi bilinmesi ve bununla birlikte farklı birçok kısa karotta yaşlandırma yapılması gerekmektedir.

\section{Teşekkür}

$\mathrm{Bu}$ çalışmanın arazi ve laboratuvar aşamalarının gerçekleştirilmesinde maddi ve manevi katkılarını sağlayan İsviçre Su Bilimleri ve Teknolojisi Federal Enstitüsü (Eawag), Yüzey Suları Bölümü öğretim üyelerinden Prof.Dr. Rolf KIPFER, Dr. Michael Sturm, Dr. Thomas KULBE ve teknisyenlerden Alois Zwyssig'e teşekkürlerimizi sunarız.

\section{Kaynaklar}

[1] Appleby P.G. 2008. Three decades of dating recent sediments by fallout radionuclides: a review. Holocene, 18 (1): 83-93.

[2] Appleby P.G., Oldfield F. 1978. The calculation of lead-219 dates assuming a constant rate of supply of unsupported $210 \mathrm{~Pb}$ to the sediment. Catena, 5 (1): 1-8.

[3] Cukur D., Krastel S., Tomonaga Y., Cagatay M.N., Meydan A.F. 2013. Seismic evidence of shallow gas from Lake Van, eastern Turkey. Marine and Petroleum Geology, 48: 341-3 53.

[4] Cukur D., Krastel S., Schmincke H.U., Sumita M., Cagatay M.N., Meydan A.F., Damc1 E., Stockehecke M. 2014. Seismic stratigraphy of Lake Van, eastern Turkey. Quaternary Science Reviews, 104: 63-84. 
[5] Cukur D., Krastel S., Tomonaga Y., Schmincke H.U., Sumita M., Meydan A.F., Çağatay M.N., Toker M., Kim S.P., Kong G.S., Horozal Ş. 2017. Structural characteristics of the Lake Van Basin, eastern Turkey, from high-resolution seismic reflection profiles and multibeam echosounder data: geologic and tectonic implications. International Journal of Earth Science, 106 (1): 239-253.

[6] Kempe S., Kazmierczak J., Landmann G., Konuk T., Reimer A., Lipp A. 1991. Largest Known Microbialites Discovered in Lake Van, Turkey. Nature, 349 (6310): 605-608.

[7] Reimer A., Landmann G., Kempe S. 2009. Lake Van, Eastern Anatolia, Hydrochemistry and History. Aquatic Geochemistry,15 (1-2): 195-222.

[8] Degens E.T., Wong H.K., Kempe S., Kurtman F.A. 1984. Geological Study of Lake Van, Eastern Turkey. Geologische Rundschau, 73 (2): 701-734.

[9] Lemcke G., Sturm M. 1997. delta O-18 and trace element measurements as proxy for the reconstruction of climate changes at Lake Van (Turkey): Preliminary results. Nato Asi Ser Ser I., 49: 653-678.

[10] Keskin M. 2003. Magma generation by slab steepening and breakoff beneath a subductionaccretion complex: An alternative model for collision-related volcanism in Eastern Anatolia, Turkey. Geophysical Research Letters, 30 (24): 1-4.

[11] Sengor A.M.C., Ozeren S., Genc T., Zor E. 2003. East Anatolian high plateau as a mantlesupported, north-south shortened domal structure. Geophysical Research Letters, 30 (24).

[12] Sumita M., Schmincke HU. 2013. Impact of volcanism on the evolution of Lake Van I: evolution of explosive volcanism of Nemrut Volcano (eastern Anatolia) during the past > 400,000 years. Bulletin of Volcanology, 75 (5).

[13] Sumita M., Schmincke H.U. 2013. Impact of volcanism on the evolution of Lake Van II: Temporal evolution of explosive volcanism of Nemrut Volcano (eastern Anatolia) during the past ca. 0.4 Ma. Journal of Volcanology Geothermal Research, 253: 15-34.

[14] Litt T., Anselmetti F.S. 2014. Lake Van deep drilling project PALEOVAN. Quaternary Science Reviews, 104: 1-7.

[15] Wong H.K, Degens E.T. 1978. The bathymetry of Lake Van: a preliminary report. In: Degens ET, Kurtman F, editors. Geology of Lake Van169. Anakara: M.T.A Press, 20-7.

[16] Litt T., Krastel S., Sturm M., Kipfer R., Orcen S, Heumann G., Franz S.O., Ülgen U.B., Neissen F. 2009. 'PALEOVAN', International Continental Scientific Drilling Program (ICDP): site survey results and perspectives. Quaternary Science Reviews, 28 (15-16): 1555-1567.

[17] Krishnaswamy S., Lal D., Martin J.M., Meybeck M. 1971. Geochronolgy of lake sediments. Earth Planet Science Letters, 11 (1-5): 407-414.

[18] Stockhecke M., Sturm M., Brunner I., Schmincke H.U., Sumita M., Kipfer R., Cukur D., Kwiecien O., Anselmetti F.S. 2014. Sedimentary evolution and environmental history of Lake Van (Turkey) over the past 600000 years. Sedimentology, 61 (6): 1830-1861.

[19] Landmann G., Reimer A., Lemcke G., Kempe S. 1996. Dating Late Glacial abrupt climate changes in the 14,570 yr long continuous varve record of Lake Van, Turkey. Palaeogeography Palaeoclimatology Palaeoecology, 122 (1-4): 107-118.

[20] Landmann G., Reimer A., Kempe S. 1996. Climatically induced lake level changes at Lake Van, Turkey, during the Pleistocene/Holocene transition. Global Biogeochemical Cycles, 10 (4): 797808. 